\title{
GEO-LOCALIZAÇÃO DE EVENTOS EXTREMOS DE CHUVA NA BACIA HIDROGRÁFICA DO RIO PRETO - MG/RJ
} \author{
Franciele de Oliveira Pimentel ${ }^{(\mathrm{d})}$ \\ (a, b, c, d) Departamento de Geociências, Universidade Federal de Juiz de Fora. \\ (a) Mestre em geografia, daiane.evangelista.oliveira@gmail.com \\ (b) Docente PPGEO/UFJF, cassia.castro@ufjf.edu.br \\ (c) Mestre em geografia, cassis.debora@gmail.com \\ (d) Mestranda em geografia, tiele_pimentel@gmail.com
}

Daiane Eevangelista Oliveira $^{(\mathrm{a})}$, Cássia de Castro Martins de Ferreira ${ }^{(\mathrm{b})}$, Débora Couto Assis ${ }^{(\mathrm{c})}$

\section{Eixo: CLIMATOLOGIA EM DIFERENTES NIVEIS ESCALARES: MUDANÇAS E VARIABILIDADES}

\begin{abstract}
Resumo
Eventos extremos, ou arritimias, são os responsáveis pelos maiores e mais intensos transtornos que as chuvas podem causar à sociedade. Percebidos de forma mais atenta que o próprio ritmo habitual, são um tipo de alteração no regime das chuvas que necessita ser estudado, pois podem vir a trazer perdas materiais e de vida. Neste contexto, o presente estudo teve por objetivo pesquisar as excepcionalidades das chuvas na bacia hidrográfica do rio Preto-MG/RJ, identificando os eventos que seriam considerados como extremos para a climatologia da região (p95 e acima de $50 \mathrm{~mm}$ ). O banco de dados utilizado compreedeu séries meteorológicas arquivadas no Hidroweb da ANA e cartas sinóticas da marinha. A análise temporal foi realizada em planilhas do Ecxel e a espacialização dos dados em software ArcGIS10. Constatou-se que a somatória de dias com registros considerados como extremos não foi similar entre as estatísticas, nem teve uma distribuição espacial homogênea.
\end{abstract}

Palavras chave: Eventos extremos; chuva; analise estatistica.

\section{Introdução}

Eventos extremos são arritmias no ciclo habitual das chuvas e podem vir a causar inúmeros transtornos à população que não está preparada para lidar com as alterações no regime destas. A susceptibilidade frente a tais eventos, como no caso de enchentes, falta de água e deslizamentos de massa, atrelados a um planejamento espacial que ainda não consegue resguardar à ocupação humana em áreas consideradas de risco, acentuam à necessidade de buscar entender a ocorrência das excepcionalidades a partir de uma visão mais integradora (NUMES, 1990, 1997; NASCIMENTO JÚNIOR, 2013; VEYRET, 2015)

Segundo Sant'Anna Netto (2001) há diversos graus de suscetibilidade em relação ao fenômeno climático, sendo o fator econômico o principal delineador de calamidade (ou não) frente aos eventos extremos. A vulnerabilidade humana em relação às manifestações climáticas é variável 
conforme seu grau sócio-econômico e questões econômicas, em muitos casos, colocam em debate problemas sociais, que são acentuados quando a população não está preparada para lidar com as intempéries climáticas (SANTANA NETTO, 2001). O entendimento da ocorrência de tais eventos, sua magnitude e imprevisibilidade vêm, então, no sentindo de permitir uma compreensão das tipologias de tempo que mais afetam a sociedade.

Em termos climáticos, já ocorre, desde as proposições de Monteiro (1971, 1991) da Análise Rítmica como um aparato teórico-metodológico para a climatologia, uma ressalva para que o "excepcionalismo" (e por sua vez os eventos extremos) seja considerado nos estudos que prezam por uma compreensão totalitária dos elementos meteorológicos (MONTEIRO, 1991). Monteiro chega a destacar ser o excepcionalismo a discussão central de sua obra e que dentre as motivações que lhe causaram desordem (ou ordem) de pensamento e que o motivaram a aprofundar na temática do rítmo está a expressão natural hazards, a qual em tentativa de ser traduzida pelo autor, o faz refletir nas concepções de "azar", "acaso", "desgraça", "risco", "acidente", "desastre" e "catastrofismo".

Sua preocupação em entender os elementos meteorológicos a partir do sequenciamento com que se manifestam, permitindo visualizá-los e correlacioná-los considerando não apenas os valores médios, mas os padrões atípicos, de forma integrada e a partir de suas ciclicidades, viria no sentido de diminuir a susceptibilidade frente a este excepcionalismo climático que tanto poderia afetar a vida das pessoas. Esta é uma perspectiva atrelada à Climatologia Dinâmica e tem nas inter-relações e visão sistêmica algumas de suas principais bases teórico-metodológicas.

Entender os fenômenos climáticos em co-habitância com os sítios onde estão inseridos é outra relação que também se atrela à esta concepção dinâmica de interpretação dos eventos e que pode vir a mitigar os seus impactos. Conforme ressalta Santos (2014) "as áreas de ocorrência podem ter conteúdos parecidos, mas nunca idênticos" (SANTOS, 2014, p.151), a natureza das forças e dos impactos, atrelada ao fato de esses acontecerem sempre no presente, faz com que os eventos não se repitam e sempre criem novas histórias (SANTOS, 2014).

Assim, partindo de tais pressupostos, buscou-se nesta pesquisa fazer um estudo dos eventos extremos de chuva que foram registrados na bacia hidrográfica do rio Preto - MG/RJ (serie: 1973 - 2014), tendo como objetivo a identificação de quais totais seriam considerados como excepcionais para a climatologia da região e a observação da ocorrência ou não de um padrão de 
distribuição espacial de áreas propícias à sua ocorrência. Tal proposta embasaria a proposição final do estudo, que seria de formar mapas base que permitissem relacionar os eventos extremos de chuva com as características socioambientais dos locais onde estes foram registrados, tendo nessa identificação das Geo-localizações uma possibilidade de entender as geograficidades destes eventos.

A justificativa para tais estudos se encontra embasada no fato de que ainda falta à geografia o entendimento dos eventos como categoria de análise (SANTOS, 2014). A busca da Geolocalização das excepcionalidades, considerando os padrões espaciais e a identificação das áreas de maior ocorrência dos eventos, tendo como base as características sócio-ambientais de cada sítio, traria como contributo a possibilidade de proposição de mecanismos que diminuíssem os impactos frente à ocorrência dos eventos que mais afetam à sociedade.

\section{Procedimentos metodológicos}

A proposta metodológica deste estudo pôde ser dividida em duas partes. A primeira (2.1), onde se fez uma breve caracterização da área de estudo, a qual permitiria uma observação das características gerais da base territorial escolhida para a pesquisa; e uma segunda (2.2), na qual foi apresentada a metodologia utilizada para a identificação dos eventos extremos, para a espacialização dos dados e para escolha das variáveis geográficas base.

\subsection{Caracterização da área de estudo}

A bacia hidrográfica do rio Preto (figura 1) possui expressiva área de contribuição, cerca de 8.593 $\mathrm{km}^{2}$, é uma das principais sub-bacias da bacia do Paraíba do Sul e está localizada na zona da mata Mineira e terras Fluminenses adjacentes, na região Sudeste do Brasil. É uma sub-bacia da bacia do Rio Paraíba do Sul, a qual é pertencente da região hidrográfica da bacia do Atlântico Sudeste (ANA, 2013), engloba 37 municípios, dentre os quais 9 pertencentes ao estado do Rio de Janeiro e 28 ao estado de Minas Gerais, ocupa uma área de $8.593 \mathrm{~km}^{2}$ e apresenta uma população de cerca de 5.259.067 habitantes (IBGE, 2010).

Conforme ressaltado por Nimer (1979) e Cavalcanti et al (2009) é uma bacia que se localiza em uma região de transição climática, sofrendo influência da tropicalidade. Essa posição latidudinal implica numa realidade climática onde ocorrem frequentes oposições entre os sistemas extratropicais e os tropicais. O clima da região possui características diversificadas, sofrendo 


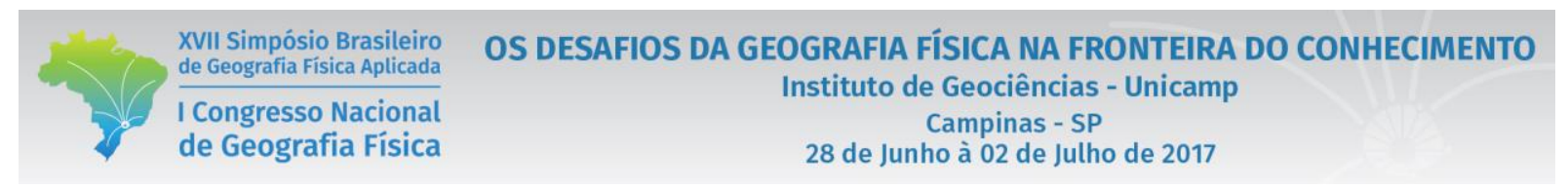

influência dos aspectos dinâmicos da atmosfera (que incluem os sistemas meteorológicos de micro, meso e grande escalas), assim como das variações nos padrões de uso e cobertura da terra e da sua situação topográfica.

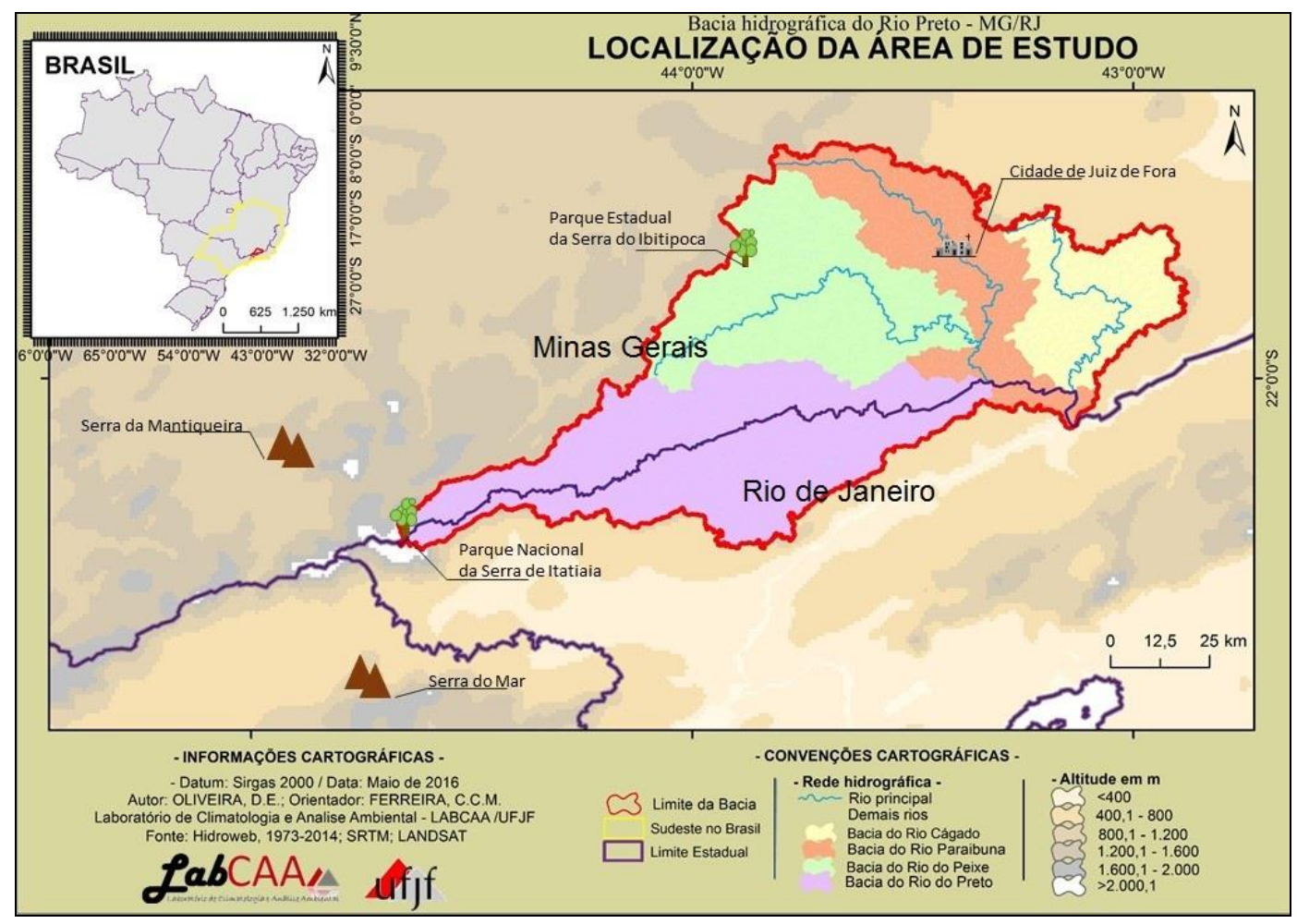

Figura 1 - Localização da área de estudo.

Inserida no Domínio Morfoclimático dos “Mares de Morro" Florestados (AB’SABER, 1970), que é caracterizado por apresentar uma sequência côncava-convexa, apresenta um relevo movimentado, variando entre 300 metros (próximo à foz) e 2700 metros (próximo a Serra de Itatiaia). As cadeias montanhosas das quais faz parte são a Serra da Mantiqueira e a Serra do Mar. Associada à ocupação do Vale do Rio Paraíba do Sul, apresenta um histórico de uso da terra que se inicia, desde o final do século XVII, pelo Ciclo Cafeeiro, e posteriormente o seu declínio, no final do século XIX, pela substituição por atividades de pecuária, extensiva e leiteira. Teve seu território configurado seguindo cada processo histórico-econômico e hoje tem como principais atividades econômicas a agropecuária e a indústria. Com base em imagens aerofotográficas, constata-se que, no que tange ao uso e cobertura que vem sendo dada a terra, apresenta uma vasta área de intervenções antrópicas com alguns fragmentos de vegetação nativa, as quais correspondem às áreas com as maiores cotas altimétricas. 
A espacialização dos processos sinóticos na bacia está condicionada principalmente ao efeito orográfico que as variações topográficas (tanto regionais, quanto locais) exercem no direcionamento, velocidade e intensidade das massas de ar, durante o percurso seguido pelos sistemas atmosféricos. A atuação predominante é das massas de ar originárias sobre o oceano e uma pequena atuação das de origem continental podem ser observadas. Estas, ao seguirem suas trajetórias influenciam nos tipos de tempo, pois carregam consigo características de seu local de origem, o que ocasiona fortes mudanças regionais em termos climáticos, podendo gerar determinada instabilidade nos lugares por onde passam (NIMER, 1979). Tais sistemas influenciam na dinâmica climática em termos regionais, uma vez que atrelados à distância em relação aos oceanos e o próprio modelado do relevo, vão formando tipos climáticos distintos.

Conforme ressalta Ferreira (2002) o padrão de circulação atmosférica também contribui para salientar os contrastes. Genericamente a área é caracterizada pela atuação mais frequente e predominante da Massa Tropical Atlântica e pela Massa Polar Atlântica, e Frentes Frias, que normalmente, na região, trazem alterações na temperatura e umidade relativa do ar, podendo ocasionar precipitações. A Zona de Convergência do Atlântico Sul (ZCAS), importante fornecedor de umidade, é um dos fatores responsáveis pelas precipitações no final da primavera e verão (FERREIRA, 2002). Apresenta duas estações bem diferenciadas: uma que vai de outubro a março, mais quente e chuvosa; e uma que vai de abril a setembro, mais fria e seca; a média anual das precipitações gira em torno de $1536 \mathrm{~mm}$ anuais na bacia (INMET, 2012).

\subsection{Metodologia}

De posse dessa base territorial que é a bacia hidrográfica do rio Preto, iniciou-se os procedimentos de criação do banco de dados. A identificação e estudo dos eventos extremos se deu de forma temporal (a partir de séries meteorológicas) e espacial (pela identificação da localização da ocorrência de eventos). A opção por trabalhar com a espacialização dos dados e a sua ocorrência na série histórica possibilitou identificar quais eventos seriam considerados atípicos e as áreas onde haveria ou não uma maior probabilidade de ocorrência de eventos extremos, assim como as características geográficas destas.

- Escala temporal

O estudo temporal foi realizado a partir da coleta dos dados meteorológicos no site hidroweb da ANA, de todas as estações que se localizavam na área de estudo e apresentavam séries com dados 
de chuva, visando utilizar o maior número de estações. Após esta coleta, e considerando que há ambientes termohigrométricos na área de estudo com caracteristicas distintas (OLIVEIRA et al, 2014, 2015), escolheu-se oito estações (figura 1) que estivessem distribuídas na área de estudo de forma mais homogênea possivel. Tomou-se o cuidado de que estas representassem às demais, considerando tantos os elementos meteorologicos, quanto as caracteristicas do sitio.

As séries foram organizadas, tiveram os dados falhos tratados estatisticamente e serviram de base para a realização de cálculos estatisticos visando a identificação dos eventos que seriam considerados como exremos para a região. Optou-se por fazer o cálculo individualmente para cada uma das 8 estações, uma vez que há divergências terminológicas na concepção do que seria um evento extremo e que este, por sua vez, varia de região para região.

A concepção de evento utilizada nesta pesquisa é a de um acontecimento que foge à habitualidade e que como tal, pode ocasionar transtornos à população. Sua identificação nas series se deu através de cálculos estatísticos, considerando duas hipóteses:

- considerando extremo apenas os eventos com volumes de chuvas intensas (igual ou superior a $50 \mathrm{~mm} / 24 \mathrm{~h}$ ), o que os identificava com base em uma classe fixa de valores;

- considerando que, pelas características de cada sitio, haveria diversos totais que poderiam ser considerados como extremos, utilizou-se do desvio percentil P95 para a identificação das classes extremas, conforme proposições de Galvani e Luchiari (2012). O emprego de tal metodologia é útil para identificar dentre os totais de precipitação quais são os que são considerados como extremos para a área de estudo.

Após a identificação dos dias com extremos de chuva fez-se a somatória dos mesmos para uma série meteorológica e por ano padrão, para cada estação teste escolhida. Nesta etapa o objetivo era contabilizar e identificar os locais de maior ou menor ocorrência de eventos extremos. A série meteorológica compreendia os anos entre 1973 e 2014 e os anos padrão foram os de 2006 (habitual), 2007 (seco) e 2008 (umido) (MONTEIRO, 1973); que são representativos da climatologia da região (OLIVEIRA, 2016). Esta foi a informação inserida durante os procedimentos de espacialização das informações.

- Escala espacial

A espacialização dos dados se deu no software ArcGIS 10 e em programas de edição de imagens. 


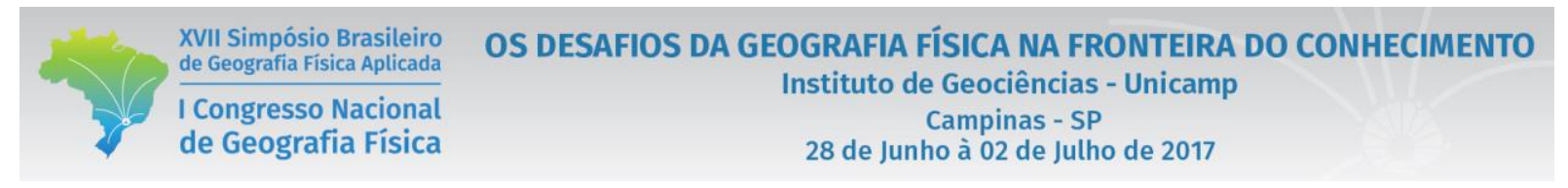

Além da plotagem dos dados pontuais referentes à somatória de eventos extremos, optou-se por também inserir informações que fossem representativas de cada sítio, para que além da localização geográfica, existisse um indicativo de outras variaveis importantes na compreenção socioambiental de cada sítio (tabela 1). A escolha das variáveis: relevo, precipitação, população e IDHM; vem no sentindo de entender as correlações entre a existência de eventos tidos como extremos e a distribuição espacial das características socioambientais destes locais.

Tabela 1 - Váriaveis para Geo-localização dos Eventos.

\begin{tabular}{|l|l|l|l|}
\hline \multicolumn{1}{|c|}{ Variável } & \multicolumn{1}{|c|}{ Justificativa } & \multicolumn{1}{c|}{ Procedimentos } & \multicolumn{1}{c|}{ Fonte } \\
\hline Relevo & $\begin{array}{l}\text { - Favorece os movimentos de massa; } \\
\text { - Influencia na formação de chuvas } \\
\text { orográficas. }\end{array}$ & - Processamento de imagens. & - SRTM \\
\hline Precipitação & $\begin{array}{l}\text { - Identificação das habitualidades e } \\
\text { excepcionalidades; }\end{array}$ & $\begin{array}{l}\text { - Coleta de dados; análise estatística; } \\
\text { - Plotagem dos dados. }\end{array}$ & $\begin{array}{l}\text { Hidroweb } \\
\text { (ANA) }\end{array}$ \\
\hline População & $\begin{array}{l}\text { - Visualização do quantitativo de } \\
\text { população que poderia ser afetada; }\end{array}$ & $\begin{array}{l}\text { - Busca no site da instituição, por } \\
\text { município. }\end{array}$ & IBGE \\
\hline IDHM & $\begin{array}{l}\text { - Observação da renda e da economia, da } \\
\text { população que vive próxima aos locais } \\
\text { de incidência ou não de eventos. }\end{array}$ & $\begin{array}{l}\text { - Busca no site da instituição, por } \\
\text { município. }\end{array}$ & IBGE \\
\hline
\end{tabular}

De posse dos levantamentos, iniciaram-se os procedimentos de análise e interpretação.

\section{Resultados}

Em relação ao número de dias com eventos estremos por anos padrão (figura 2) constatou-se que não houve similaridade das informações entre as estatísticas do P95 e do 50mm, e que apenas as estações 1 e 8 apresentaram o mesmo quantitativo de dias por ano para as duas estatísticas. $\mathrm{O}$ ponto que foi mais discrepante foi o de número 4 .

O percentil 95 gerou um resultado mais homogêneo que o cálculo acima de $50 \mathrm{~mm}$. Desta forma tanto a variação interanual quanto a distribuição espacial se mostrou correlata entre os pontos, tendo prevalecido a classe 7 dias com eventos extremos por ano (16 vezes), seguida de 5 vezes em que o total de dias com chuva foi de 6 eventos por ano e uma vez com 8,12 e 13 eventos extremos.

Por sua vez, os eventos acima de 50mm ocorreram em no máximo 13 dias por ano (2008, ponto 6), tendo locais em que não houve eventos extremos nos anos estudados, como no caso dos 
XVII Simpósio Brasileiro de Geografia Fisica Aplicada

I Congresso Nacional de Geografia Física
OS DESAFIOS DA GEOGRAFIA FÍSICA NA FRONTEIRA DO CONHECIMENTO

Instituto de Geociências - Unicamp

Campinas - SP

28 de Junho à 02 de Julho de 2017

pontos 4 (ano de 2007) e 5 (ano de 2006), ou apenas um dia considerado como extremo, como no caso dos pontos 3 e 4, ambos no ano de 2006.

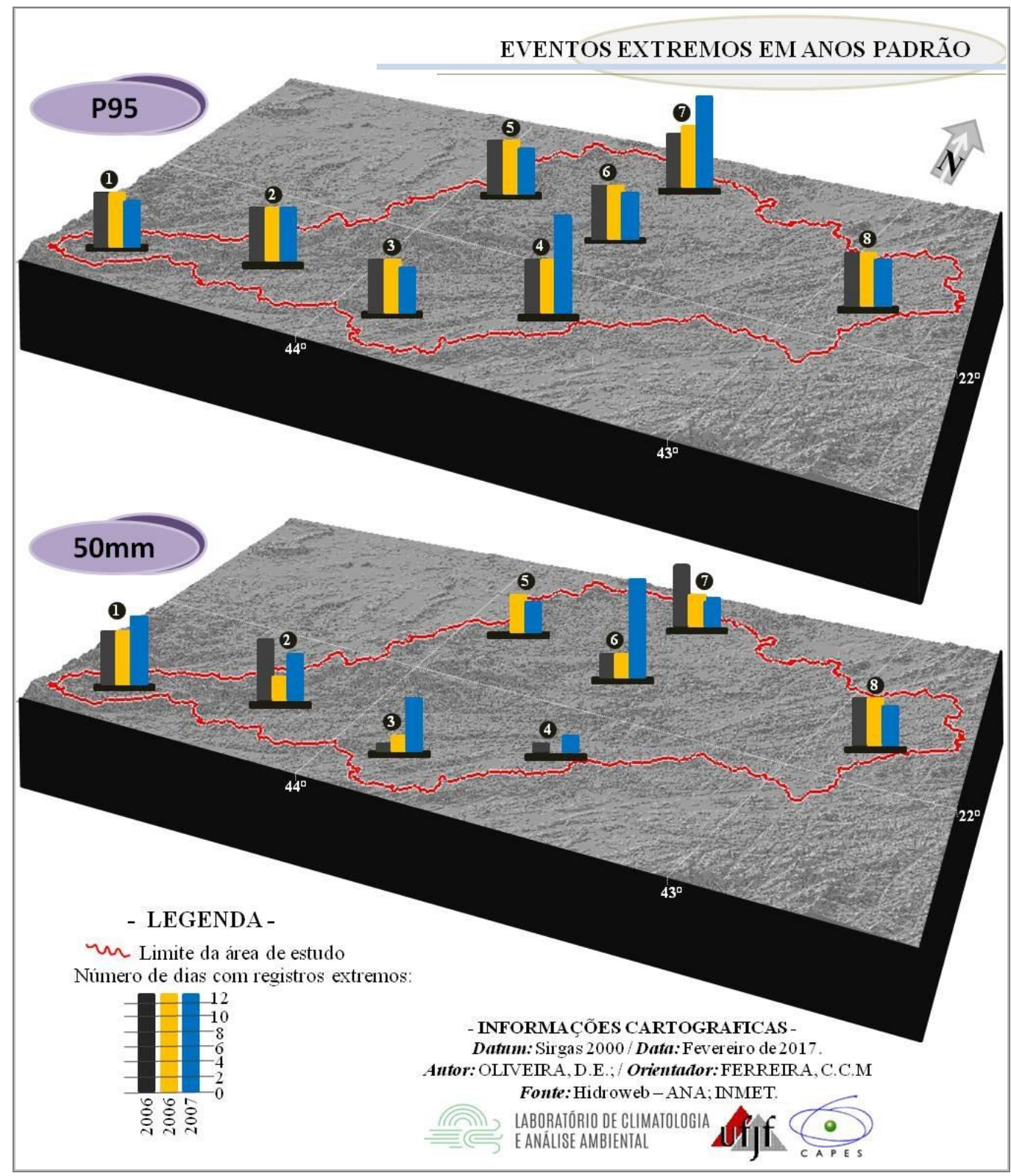

Figura 2 - Localização de eventos em anos padrão.

O desvio padrão dos dados (tabela 2) indicou que o ano seco (2007) aparesentou mais semelhança entre as duas estatísticas que os demais anos, seguido do ano habitual (2006) e do ano úmido (2008). Em relação ao desvio por ponto, o teste constatou que houve uma progressão em sentido Oeste para Leste, onde o número 1 teve a menor variação e o 8 a maior. 
Tabela 2 - Desvio Padrão entre as estatísticas.

\begin{tabular}{|c|l|r|r|r|r|}
\hline Ponto & Estação & $\mathbf{2 0 0 6}$ & $\mathbf{2 0 0 7}$ & $\mathbf{2 0 0 8}$ & \multicolumn{1}{c|}{ Desvio } \\
\hline $\boldsymbol{1}$ & FAZENDA AGULHAS NEGRAS & 2,7 & 2,3 & 3,2 & 0,4 \\
\hline $\mathbf{2}$ & ZELINDA & 3,0 & 2,6 & 3,4 & 0,4 \\
\hline $\mathbf{3}$ & CONSERVATORIA & 3,2 & 2,9 & 4,3 & 0,7 \\
\hline $\mathbf{4}$ & TABOAS & 3,4 & 2,9 & 4,6 & 0,9 \\
\hline $\mathbf{5}$ & CONCEIÇÃO DO IBITIPOCA & 3,3 & 2,6 & 4,5 & 0,9 \\
\hline $\boldsymbol{6}$ & TORREÕES & 3,1 & 2,6 & 5,0 & 1,3 \\
\hline $\boldsymbol{7}$ & CHAPEU D'UVAS & 3,2 & 2,5 & 4,5 & 1,0 \\
\hline $\boldsymbol{8}$ & ESTEVÃO PINTO & 3,0 & 2,2 & 5,0 & 1,4 \\
\hline
\end{tabular}

Em relação ao número de dias com eventos extremos para a série (figura 2), constatou-se que também o P95 apresentou homogeneidade espacial nos resultados. Para este, as somatórias estiveram entre 101 dias (Conservatória) e 116 dias (Torreões e Chapeu D’Uvas). Por sua vez, os eventos com registros acima dos 50mm estiveram entre 35 em Taboas e 102 dias em Fazenda Agulhas Negras. O desvio padrão para o primeiro cálculo foi de 21,37 e para o segundo de 7,1. No que tange a Geo-localização dos eventos (figura 2), constatou-se que em relação a altitude o ponto mais elevado (ponto 1 - Fazenda Agulhas Negras) apresentou o mesmo número de dias extremos para os dois cálculos, o que implica em dizer que nesta estação o esperado é que a precipitação registrada seja de um total mais elevado. O que é comprovado considerando que a média anual dos totais de precipitação neste ponto seja de $2404,7 \mathrm{~mm}$. Os pontos 2, 3, 4, 6 e 8 estiveram na mesma classe altimétrica (entre 400-600 metros).

Dois pontos que necessitam ser destacados são os de números 6 e 7. Estes se localizam no mesmo município, mas em locais com altitudes distintas, 442m (ponto 6) e 970m (ponto 7). Juiz de Fora é o mais populoso dos municípios estudados e com o melhor Índice de Desenvolvimento Humano Municipal (IDHM, IBGE, 2010) $(0,778)$ o que a coloca como pólo regional. Nestes pontos foram registrados o segundo maior quantitativo de dias com eventos extremos acima de 50mm, (Torreões, ponto 6, com 95 dias) e o maior quantitativo para o p95, com 116 dias em ambos pontos (Torreões e Chapeu D'Uvas).

Em uma primeira análise poderia ser constatado que por ter um índice considerado bom de desenvolvimento humano tal município seria o menos prejudicado com a ocorrência de tantas excepcionalidades, pois a população estaria mais consciente de que co-habitam áreas de risco. No entanto, sempre há registros midiáticos que comprovam que a população vem sofrendo com estas calamidades. $\mathrm{O}$ ponto 7 se localiza nesta área urbana e tem em seus registros comprovações de 


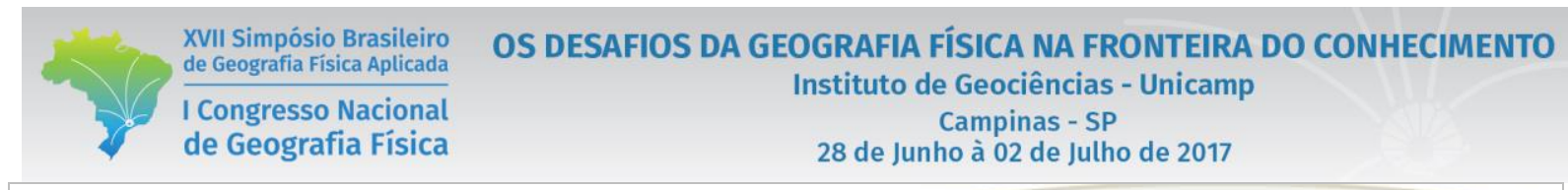

\section{GEOLOCALIZAÇÃO DE EVENTOS EXTREMOS}

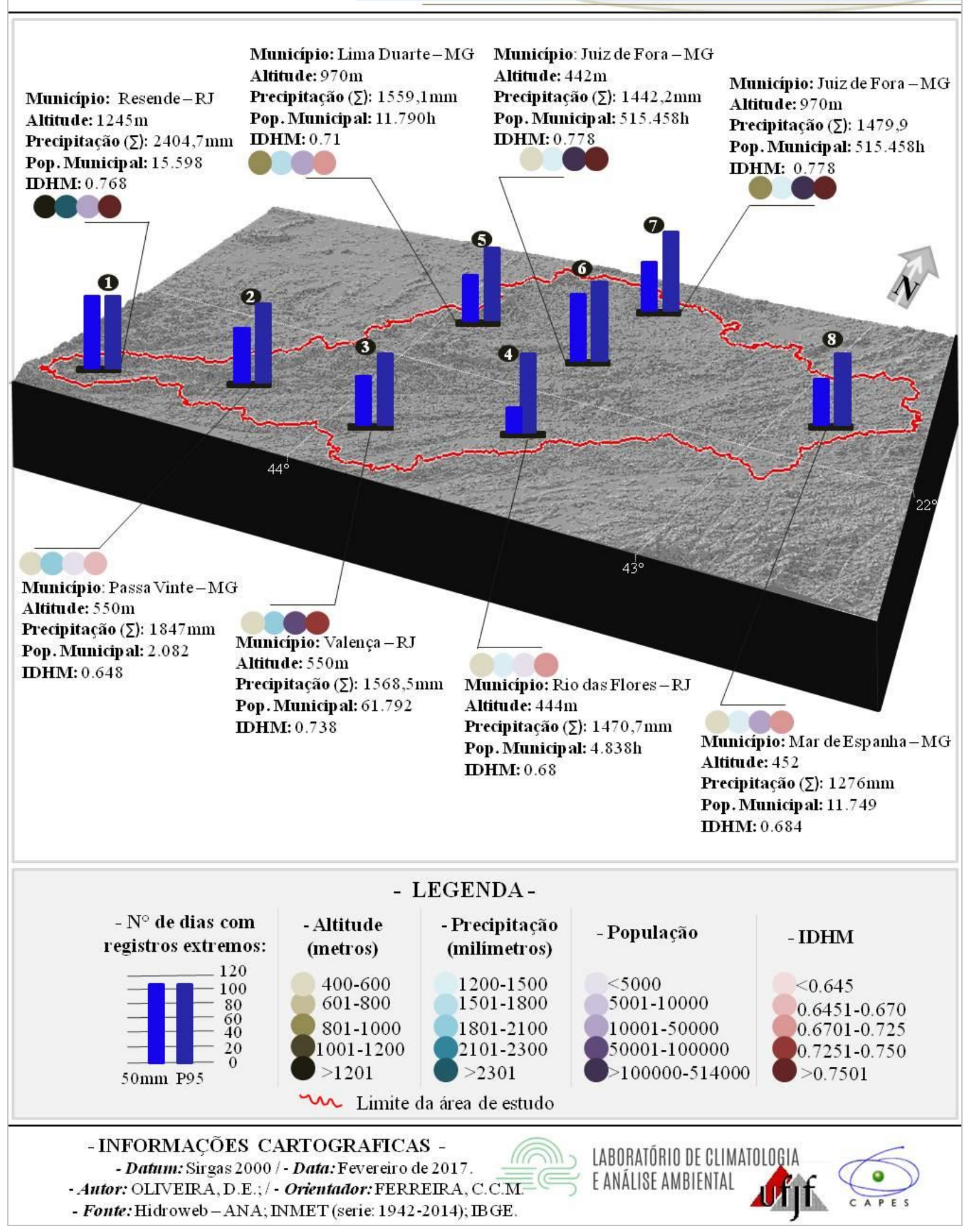

Figura 3 - Localização de eventos série: 1974 - 2014. 
que há muitas ocorrências de excepcionalidades nessa área.

Dois fatos precisam ser considerados a este respeito. $\mathrm{O}$ primeiro é que por ser o mais populoso, o quantitativo de pessoas que podem ser diretamente afetadas com os eventos extremos será grande, principalmente se considerarmos que $98,9 \%$ de sua população vive no perímetro urbano (Censo Demográfico, IBGE, 2010) de forma concentrada. O outro fato é que é uma área de relevo acidentado (os pontos 6 e 7 se localizam a 442m e 970m de altitude respectivamente) (AB'SABER, 1970) o que acentua as áreas consideradas de risco (ROCHA, 2005), principalmente se for considerado que há habitações tanto nas calhas dos rios quanto nas vertentes dos morros. O planejamento municipal ainda não é eficaz e acentua as calamidades oriundas das excepcionalidades climáticas.

\section{Considerações finais}

O trabalho possibilitou observar que não há uma similaridade nos padrões encontrados para as estatísticas utilizadas, o que permite dizer que os extremos de chuva que foram registrados na área de estudo não superaram, na maior parte dos pontos, os 50mm de chuva. Apenas no ponto 1, onde os totais anuais podem chegar aos $2404,7 \mathrm{~mm}$, foi comum o registro de dias que superaram esse total.

O município mais populoso (Juiz de Fora) e com o melhor IDHM da área de estudo engloba os pontos 6 e 7 e esteve dentre os que apresentaram os maiores quantitativos de dias com eventos extremos. Neste, constata-se que há urgência em se (re)pensar as leis de planejamento e parcelamento dos solos, pois além de se localizar em uma área propícia a registrar totais elevados de chuva, possui um perimetro urbano que se construiu a partir do fundo do vale do rio Paraibuna e que seguindo o relevo típico da região ("Mares de Morro" - AB'SABER, 1970) apresenta inúmeras áreas consideradas de risco, podendo vir a sofrer com enchentes e movimentos de massa.

O estudo permitiu localizar espacialmente os eventos e observar brevemente as características dos locais de maior ou menor ocorrência. No entanto, há ainda que se aprofundar nas análises, para que a ocorrência dos eventos extremos de chuva na bacia hidrográfica do rio Preto, seja conhecida e traga cada vez mais menos transtornos à população. 


\section{Bibliografia}

- ANA - Agencia Nacional das Águas. http://hidroweb.ana.gov.br/

- AB’SÁBER, A. N. Províncias geológicas e domínios morfoclimáticos no Brasil. Geomorfologia: São Paulo. 1970.

- CAVALCANTI, I. F.A.; FERREIRA, N.J.; SILVA, M.G.A.J.; DIAS, M.A.F.S. Tempo e clima no Brasil. Oficina de textos: São Paulo. 2009.

- IBGE - INSTITUTO BRASILEIRO DE GEOGRAFIA E ESTATISTICA. http://cidades.ibge.gov.br/xtras/home.php/

- FERREIRA, C. C. M. Tipos de tempo de categorias climáticas na Bacia do Rio Paraibuna - MG. São Paulo: USP, 2002. Tese (Doutorado), Universidade de São Paulo.

- GALVANI, E.; LUCHIARI, A. Critérios para classificação de anos com regime pluviométrico normal, seco e úmido. In: GALVANI, E.; LIMA, N. G. B. Climatologia aplicada: resgate aos estudos de caso. 1. Ed. Curitiba: CRV, 2012.

- NASCIMENTO JÚNIOR, L. As chuvas no Paraná: Variabilidade, teleconexões, e impactos de eventos extremos. 2013. Presidente Prudente: UNESP. 2013. Dissertação (mestrado) -

- NIMER, E. Climatologia do Brasil. Instituto Brasileiro de Geografia e Estatística: Rio de Janeiro. 1979.

- MONTEIRO, C. A. M. Análise rítmica em climatologia: problemas da atualidade em São Paulo e achegas para um programa de trabalho. Instituto de Geografia da USP: São Paulo. 1971.

- MONTEIRO, C. A. F. A dinâmica climática e as chuvas do estado de São Paulo: estudo geográfico sob forma de atlas. IGEOG: São Paulo. 1973.

- MONTEIRO, C.A.F.M. Clima e excepcionalismo: conjecturas sobre o desempenho da atmosfera como fenômeno geográfico. UFSC: Florianópolis. 1991.

- NUMES, L.H. Impacto Pluvial na Serra do Paranapiacaba e Baixada Santista. São Paulo: USP, 1990. Dissertação (Mestrado), Universidade de São Paulo.

- NUMES, L.H. Distribuição espaço-temporal da pluviosidade no Estado de São Paulo: tendências, variabilidade, processos intervenientes. São Paulo: USP, 1997. Tese (Doutorado), Universidade de São Paulo.

- OLIVEIRA, D.E.; ASSIS, D.C.; FERREIRA, C.C.M.; Definição de unidades climáticas para a bacia hidrográfica do rio Paraibuna, MG/RJ. In: Simpósio Brasileiro de Climatologia Geográfica, 2014, CuritibaPR diponilizado em midia (pendrive do evento).

- OLIVEIRA, D.E.; ASSIS, D.C.; FERREIRA, C.C.M. Distribuição espacial da sazonalidade nos tipos de tempo para a bacia do rio Preto, MG/RJ. In: XI Encontro da ANPEGE, 2015, Presidente Prudente-SP. Cd de Anais, 2015.

- OLIVEIRA, D. E. Participação dos sistemas atmosféricos na gênese e ritmo das chuvas na bacia hidrográfica do rio Preto, MG/RJ - anos de 2006, 2007, 2008. Juiz de Fora: UFJF, 2016. Dissertação (Mestrado), Universidade Federal de Juiz de Fora.

- ROCHA, G. C. Riscos Ambientais: Analise e Mapeamento em Minas Gerais. UFJF: Juiz de Fora. 2005.

- SANT'ANNA NETO, J.L. Por uma Geografia do Clima, antecedentes históricos, paradigmas contemporâneos e uma nova razão para um novo conhecimento. Revista Terra Livre, $\mathrm{n}^{\circ} 17,2^{\circ}$ semestre de 2001, p. 49-62.

- SANTOS, M. A natureza do espaço. Hucitec: São Paulo. 1996. Reimpressão 2014.

- VEYRET, Y. Os riscos: O homem como agressor e vitima do meio ambiente. Contexto: São Paulo. 2003. Reimpressão 2015. 